\title{
The effects of bar width and spatial frequency-specific adaptation on visual persistence
}

\author{
GLENN E. MEYER \\ Lewis and Clark College, Portland, Oregon 97219 \\ and \\ W. M. MAGUIRE \\ Division of Neurobiology, State University of New York at Buffalo \\ School of Medicine, 4234 Ridge Lea, Amherst, New York 14226
}

\begin{abstract}
Two experiments investigated the properties of visual persistence as functions of spatial frequency, stimulus duration, and pattern-specific adaptation. Experiment 1 demonstrated that the perceived duration of sine-wave gratings presented for 50 msec increased from 250 . to $500 \mathrm{msec}$ as spatial frequency ranged from .4 to 6.4 cycles per degree of visual angle. Similarly, visual persistence for single bars increased as their widths decreased. Experiment 2 found that adaptation to a specific spatial frequency reduced the perceived duration of gratings that were close to the adaptation value in spatial frequency.
\end{abstract}

The discovery that a briefly presented visual target remains perceptually present for some time after the offset of the physical stimulus (Sperling, 1960) has generated great interest and some controversy. This phenomenon is known as iconic memory or visual persistence. One problem that recently has drawn attention is that of the locus of the icon. While some have claimed that the major component of this shortterm visual storage (STVS) is situated in the rod photoreceptor (Sakitt, 1975), recent studies have indicated the importance of both cone and postphotoreceptor processing to the icon (Banks \& Barber, 1977; Meyer, 1977; Meyer, Lawson, \& Cohen, 1975; Meyer \& Maguire, 1977).

In our work, we have been interested in the interactions of dimensions, thought to be important to cortical visual mechanisms, with the functioning of visual persistence. If a grating of a particular orientation and color is presented as an adaptation stimulus, the persistence of a grating of similar orientation and color is shortened, while gratings of different orientation and color are not affected (Meyer, 1977; Meyer et al., 1975).

In a previous paper (Meyer \& Maguire, 1977), we found with gratings above 2 cycles per degree of visual angle (c/d) that persistence increased as the spatial frequency of the grating increased. This result was

These experiments were run while G. E. Meyer was at the Division of Neurobiology, State University of New York at Buffalo School of Medicine, and W. M. Maguire was at the Department of Psychology, State University of New York at Buffalo. G. E. Meyer and W. M. Maguire were supported by NEI Grant 5T32 EY07019-01. Send requests for reprints to G. E. Meyer, Lewis and Clark College, Portland Oregon 97219. consistent with results showing that reaction time increases with increasing spatial frequency (Breitmeyer, 1975; Vassilev \& Mitov, 1976), and that critical duration (on-time/luminance reciprocity at threshold) likewise increases with increasing spatial frequency (Breitmeyer \& Ganz, 1977). The above results appear to indicate that the mechanisms that encode the higher spatial frequencies respond more slowly and integrate stimulus energy over a longer time period.

In the present paper, we report two experiments. The first was a replication of our original study (Meyer $\&$ Maguire, 1977) using sine-wave rather than squarewave gratings. The second tested the possibility of spatial frequency-specific adaptation on visual persistence.

\section{EXPERIMENT 1: VISUAL PERSISTENCE OF SINE-WAVE GRATINGS AND SINGLE BARS}

This experiment was performed to check on the original results of Meyer and Maguire (1977), where the visual persistence of square-wave gratings was found to increase with increasing spatial frequency. The present use of sine-wave gratings mitigates possible distortions of the persistence by spatial frequency function by the higher frequency edge components in the stimuli. Additionally, we wished to ascertain whether the increased persistence observed with increasing grating periodicity was not simply due to the increasing number of bars present in the field at high spatial frequencies. One might conjecture that bars of a grating fade individually and that the subjects might base their judgments of persistence on the last bar to disappear. On a proba- 
bilistic basis, this could lead to longer persistence as spatial frequency increases. We therefore measured the persistence of single bars differing in width.

\section{Method}

Subjects. The authors (GM and WM) served as subjects in this and later experiments. WM has normal uncorrected acuity; GM has corrected acuity.

Apparatus. The stimuli consisted of five sine-wave gratings $(.4, .8,1.6,3.2$, and $6.4 \mathrm{c} / \mathrm{d})$ of .5 contrast, subtending $5.25 \mathrm{deg}$ vertically by 7.5 deg horizontally. Also two bars of rectangular profile were used. They measured $5.25 \mathrm{deg}$ vertically and were 15.8 and $2 \mathrm{~min}$ wide. Their widths corresponded, respectively, to a half-cycle of a $1.9-$ or $15-c / d$ grating. These stimuli were dark on the light background and of high contrast (.9).

The stimuli were presented monocularly in a Scientific Prototype six-channel tachistoscope. The space average luminance of the field was $5 \mathrm{ftL}$ for both sine-wave stimuli and bar stimuli, which were presented in different channels. A blank field of the same space average luminance was present in a third channel.

Procedure. A sine wave or bar presented for $50 \mathrm{msec}$ was continuously alternated with the variable-duration blank field. The order of target testing was random. Under the subject's instructions, the experimenter adjusted the blank field duration to the point where the stimulus was just continuously present or just interrupted by the blank field. Each criterion was used on half of the trials. The average of the adjustments was taken as a measure of the persistence of the stimulus. This is an adaptation of the method used by Haber and Standing (1970) and generates reliable estimates of visual persistence (Meyer, 1977; Meyer et al., 1975; Meyer \& Maguire, 1977). Each subject performed six adjustments for each of the seven stimuli.

\section{Results and Discussion}

The data are shown in Figure 1, where it is clear that for sine-wave stimuli, the persistence increases with spatial frequency. In addition, the thinner bar clearly exhibits a longer persistence than the wide bar. Individual subject analyses of variance were performed upon the data. Both subjects showed the overall effects of spatial frequency to be significant $[\mathrm{GM}, \mathrm{F}(4,35)=8.3$,

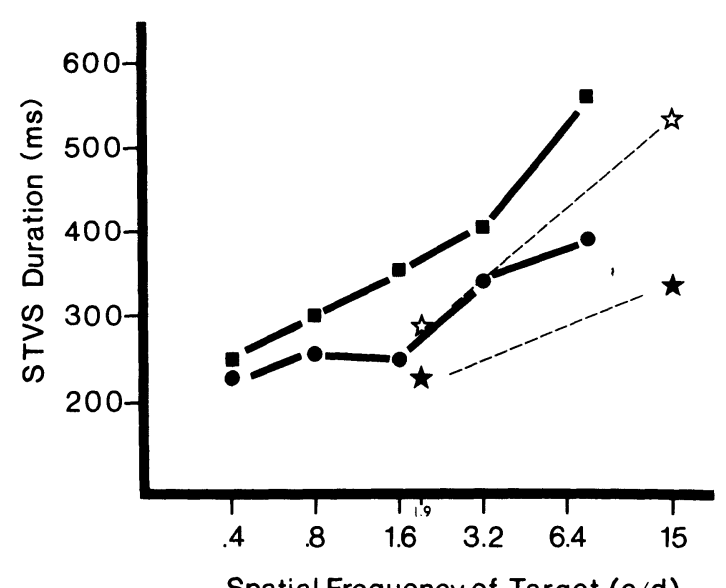

Spatial Frequency of Target (c/d)

Figure 1. Duration of short-term visual storage for sine-wave gratings and single bars. Solid squares ( $(\bullet)$ and empty stars (ㅅ) represent, respectively, grating and bar data for W.M. Solid circles $(\bullet)$ and solid stars $(\star)$ similarly mark grating and bar data for G.M. $\mathrm{p}<.01 ; \mathrm{WM}, \mathrm{F}(4,35)=15.4, \mathrm{p}<.011$. The aperiodic stimuli also differed significantly from each other [WM, $\mathrm{t}(10)=19.5, \mathrm{p}<.01 ; \mathrm{GM}, \mathrm{t}(10)=23.8, \mathrm{p}<.01]$. Thus the results for sine waves and bars parallel the results reported with square waves (Meyer \& Maguire, 1977). The qualitative similarity of aperiodic and periodic persistence estimates makes unlikely the possibility that high-frequency stimuli have longer subjective durations simply because there are more bars in the field. The results do conform with the previously mentioned results reporting increased reaction time as spatial frequency increases. If bars are responded to individually and there is some randomness, reaction time would decrease with increasing elements in the field, as response was keyed to the first available bar. Such effects are common in studies of human information processing (Biederman \& Chekosky, 1970). These results and reaction time results support rather the theoretical viewpoint that size channels within the visual system exhibit different temporal characteristics.

\section{EXPERIMENT 2: SPATIAL FREQUENCY-SPECIFIC ADAPTATION OF VISUAL PERSISTENCE}

Previous work has demonstrated that subjects' estimates of visual persistence can be shortened by orientation, conjoint color and orientation, and retinal disparity-specific adaptation (Meyer, 1977; Meyer et al., 1975; Van der Meer, 1976). In Experiment 2 we attempted to see if changes in visual persistence could be tied to spatial frequency-specific adaptation. The psychophysical literature currently abounds with phenomena manifesting frequency specificity (Breitmeyer \& Cooper, 1972; DeValois, 1977; Meyer, 1974), and we expected that iconic duration would show similar effects. The authors again served as subjects.

\section{Method}

The test procedure was the same as in Experiment 1. However, in this study, square-wave gratings of high contrast (.99) and with spatial frequencies of .9,1.9, 3.8, 7.5, and $15 \mathrm{c} / \mathrm{d}$ were used as targets. Space average luminance of target grating and blank field was again $5 \mathrm{ftL}$. Each adaptation grating was run on a separate day. Both subjects were tested with the 3.8and $7.5-\mathrm{c} / \mathrm{d}$ adaptation patterns. The procedure was as follows. The observer began by running a series of control trials. These consisted of adapting to the blank field for $3 \mathrm{~min}$. Immediately thereafter, the target gratings were presented randomly and sequentially for persistence judgments. The observer repeated this procedure five times. After a brief rest period, the procedure was repeated with the adapting pattern substituted for the blank field during the adapting period. In this manner, a set of five observations for each adapting and associated control pattern was collected for each test frequency.

\section{Results and Discussion}

The data are presented in Figure 2. Panel A represents the means of the blank adaptation conditions for G.M. and W.M. Visual persistence or STVS duration again is shown to increase with spatial frequency. Figure 2B 

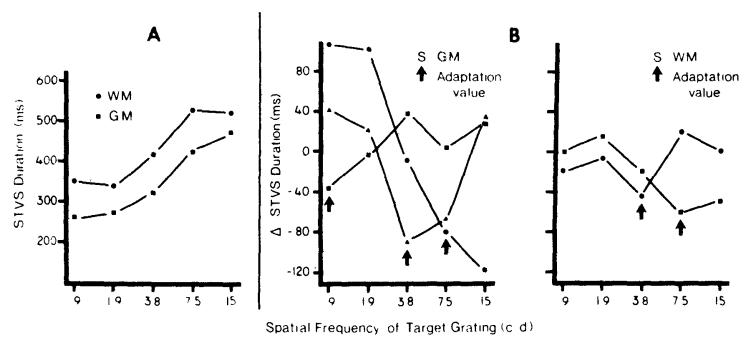

Figure 2. (A) Duration of short-term visual storage for squarewave gratings after adaptation to a blank field. (B) Difference scores in visual persistence for G.M. and W.M. after grating adaptation. $\triangle$ STVS represents the grating mean after grating adaptation minus the grating mean from the previous blank adaptation condition for that grating.

plots the change in persistence due to adaptation calculated by taking the mean difference between adaptation and associated blank control trials. Note that visual persistence is shortened in the region corresponding to adaptation spatial frequency. A withinsubjects analysis of variance for the means of the 3.8and $7.5-\mathrm{c} / \mathrm{d}$ adaptation conditions and controls showed a significant effect of spatial frequency $[\mathrm{F}(4,14)=11.18$, $\mathrm{p}<.01]$ and Adaptation by Spatial Frequency interaction $[F(8,14)=2.70, p<.05]$.

The graphs show that visual persistence is indeed subject to spatial frequency adaptation. An interesting note is that the duration of other gratings may show some enhancement. Similar results have been reported with orientation (Meyer et al., 1975) and disparityspecific adaptation (Van der Meer, 1976) of visual persistence. Also, DeValois (1977) recently found enhancement of contrast sensitivity at target frequencies relatively far from the adaptation frequency for adapting gratings.

In conclusion, the increase of visual persistence with spatial frequency does not seem to be an artifact of the number of bars in the grating. Instead, neural factors relating to the sensitivity of sustained channels to high spatial frequencies seems the crucial factor (Meyer \& Maguire, 1977). Also, visual persistence can be shortened by spatial frequency-specific adaptation. This was to be expected, given previous findings of orientation (Meyer et al., 1975), color (Meyer, 1977), and retinal disparity-specific (Van der Meer, 1976) decrements in STVS.

\section{REFERENCES}

Banks, W. P., \& Barber, G. Color information in iconic memory. Psychological Review, 1977, 84, 536-546.

Biederman, I., \& Checkosky. Processing redundant information. Journal of Experimental Psychology, 1970, 83, 486-490.

Breitmeyer, B. G. Simple reaction time as a measure of the temporal properties of transient and sustained channels. Vision Research, 1975, 15, 1411-1412.

Breitmeye R, B. G., \& Cooper, L. A. Frequency specific color adaptation in the human visual system. Perception \& Psychophysics, 1972, 11, 95-96.

Breitmeyer, B. G., \& Ganz, L. Temporal studies with flashed gratings: Inferences about human transient and sustained channels. Vision Research, 1977, 17, 861-866.

DEV ALOIS, K. K. Spatial frequency adaptation can enhance contrast sensitivity. Vision Research, 1977, 17, 1057-1065.

Haber, R. B., \& Standing, L. G. Direct measures of shortterm visual storage. Quarterly Journal of Experimental Psychology, 1969, 21, 43-54.

Meyer, G. E. Pressure blindness and the interocular transfer of size aftereffects. Perception \& Psychophysics, 1974, 16, 222-224.

MEYER, G. E. The effects of color-specific adaptation of the received duration of gratings. Vision Research, 1977, 17, 51-56.

Meyer, G. E., Lawson, R., \& Cohen, W. The effects of orientation-specific adaptation on the duration of short-term visual storage. Vision Research, 1975, 15, 569-572.

Meyer, G. E., \& Maguire, W. M. Spatial frequency and the mediation of short-term visual storage. Science, 1977, 190, 1318-1319.

SAKITT, B. Locus of short-term visual storage. Science, 1975, 190, 1318-1319.

SPERLing, G. The information available in brief visual presentations. Psychological Monographs, 1960, 74(Whole No. 498).

VAN DER MEer, H. C. The effects of adaptation to stereoscopic depth and to uniocular image magnification on the duration of short-term visual storage. Acta Psychologica, 1976, 40, 311-323.

Vassilev, A., \& Mitov, D. Perception time and spatial frequency. Vision Research, 1976, 16, 89-92.

(Received for publication April 11, 1979.) 